\title{
An alternative mining method at the Kvannevann Mine, northern Norway
}

\author{
S. Nævermo Sand Rana Gruber AS, Norway
}

\begin{abstract}
After more than 30 years of open pit mining, in 2000 Rana Gruber AS started underground mining using the sublevel open stoping method at the Kvannevann Mine, located in northern Norway. The mining has been continuously improved and further developed to suit the difficult rock conditions in the area and to reduce operating costs. A combination of low grade iron ore (with on average $33 \%$ iron (Fe)) and significant rock mechanics challenges (large horizontal stresses) has made mining in the Kvannevann Mine extraordinary. Because of the last year's increase of production due to the demand for iron ore, Rana Gruber AS investigated methods to increase the mining capacity and resources. This resulted in an evaluation of alternative mining methods. The investigation resulted in the decision to change over from sublevel open stoping to sublevel caving. Key arguments were: a) mineable reserves; b) cost and benefit with respect to investment; c) extraction values show an optimistic and satisfactory result; and d) estimations and field tests indicating a satisfactory caving of the deposit.
\end{abstract}

\section{Introduction}

The Kvannevann Mine is one of several iron ore mines operated and owned by Rana Gruber AS in the Dunderland Valley. The Kvannevann Mine is the only underground mine in the region. The deposit is located in the northern part of Norway, approximately $50 \mathrm{~km}$ south of the Arctic Circle. Today, Rana Gruber AS combines underground and open pit mining methods and produces iron ore concentrates for multiple purposes. The majority of the concentrates are designated for iron and steel production, while smaller quantities are tailored for special applications. The main steps of the process are: mining, crushing and storage of crude ore at the $\emptyset$ rtfjell deposit. Then railway transport to the dressing plant in Mo I Rana, a distance of approximately $35 \mathrm{~km}$, mineral dressing and concentration, storage of concentrates and supply to customers via our own shipping terminal.

During 2008, Rana Gruber AS was taken over by Leonhard Nilsen \& Sønner AS, (LNS) a company with an international reputation in tunnelling, excavation of rock and construction. The new owners immediately focused on the investigation of alternative mining methods in order to increase the production and lower the mining costs with the overall aim of maintaining long term mining of iron ore in the area.

A project group with both internal and international participants was put together to carry out the task. From the beginning of the investigation program, sublevel caving appeared to be the most feasible alternative for the mine. The objective of the investigations was to collect all necessary information about the physical conditions of the mining area and to look into the operating parameters and the cost structure for the alternative mining method. This was done in order to create a satisfactory database capable of guiding Rana Gruber AS to a final judgement about the risks and benefits involved with the change from a known to a new mining method. Several numerical models were built to play with variables and to help find the best solutions. Caving of the sidewalls is a necessary ingredient for successful sublevel caving. The main focus was therefore put on the investigation of the hangingwall and footwall of the deposit and their ability to cave. 


\section{The Ørtfjell deposit, ore base of the Kvannevann orebody}

The $\emptyset$ rtfjell iron ore deposit is embedded in meta-sediments and meta-volcanic of probable proterozic age -1.2 billion years old. The geological rock unit is today made up of mica schists, calcareous garnet-mica schists, limestones and small layers of amphibolites and quartzites. The rocks show a distinct foliation due to a severe tectonic overprint represented by at least three folding cycles. The iron ore is in direct contact with either the limestones or the mica schists. As the result of isoclinals folding, the thickness of the iron ore deposit is several times its original thickness. The ore is more or less banded due to varying iron oxide concentrations. The orebodies in the $\varnothing$ rtfjell area show an outcrop with a U-shaped pattern with its axis in almost an east-west direction (Figure 1). In the western part of the area, the dip of the fold axis is $65^{\circ}$ towards the east while they dip $25^{\circ}$ towards the west in the eastern areas. This indicates a structure similar to an elongated bowl for the iron ore concentrations. The flanks of the bowl-like structure dip steeply towards the north and south respectively. The bottom of the bowl is calculated to be found approximately 1,500 to $2,000 \mathrm{~m}$ from surface based on the tectonic data available today.

The Kvannevann Mine is located on the southern flank of the U-shaped structure. The currently mined ore has an extension of $1,200 \mathrm{~m}$ with thicknesses varying from $30 \mathrm{~m}$ up to more than $100 \mathrm{~m}$. The orebody has been proven to continue from surface (at average $450 \mathrm{~m}$ above sea level) to $10 \mathrm{~m}$ below sea level by diamond drilling and exploration tunnelling. The iron ore consists of flaky hematite (also known as specularite) and magnetite which amounts on average to $50 \%$ of the iron ore. The accompanying host minerals are Fe-containing silicates, carbonates, small amounts of apatite and traces of iron sulphides. Hematite is the predomina iron oxide making up on average $97 \%$ of the total oxides. The total Fe-content of the ore varies between $27-35 \%$, and averages $33 \%$.

During the years of exploration and mining a total of $100 \mathrm{~km}$ of diamond drill core has been evaluated to map the extension and quality of the ore, to the boundaries of the orebody and to document areas of rock weakness due to tectonic stress. The findings from core logging and analytical works were digitalised for further data processing as an initial task of the current project. The work resulted in an improved geometric model for the orebody (shown in Figure 1), clarified ore boundaries in areas with complex interlocking of waste rock, pointed out areas with elevated values of undesired elements and provided a more reliable calculation of the iron content for each ore block and mining level. The digitalisation of the tectonic data were of high relevance to the planning of the infrastructure and safety tasks in the mine as they revealed fracture zones, joints, faults and areas with high shear.

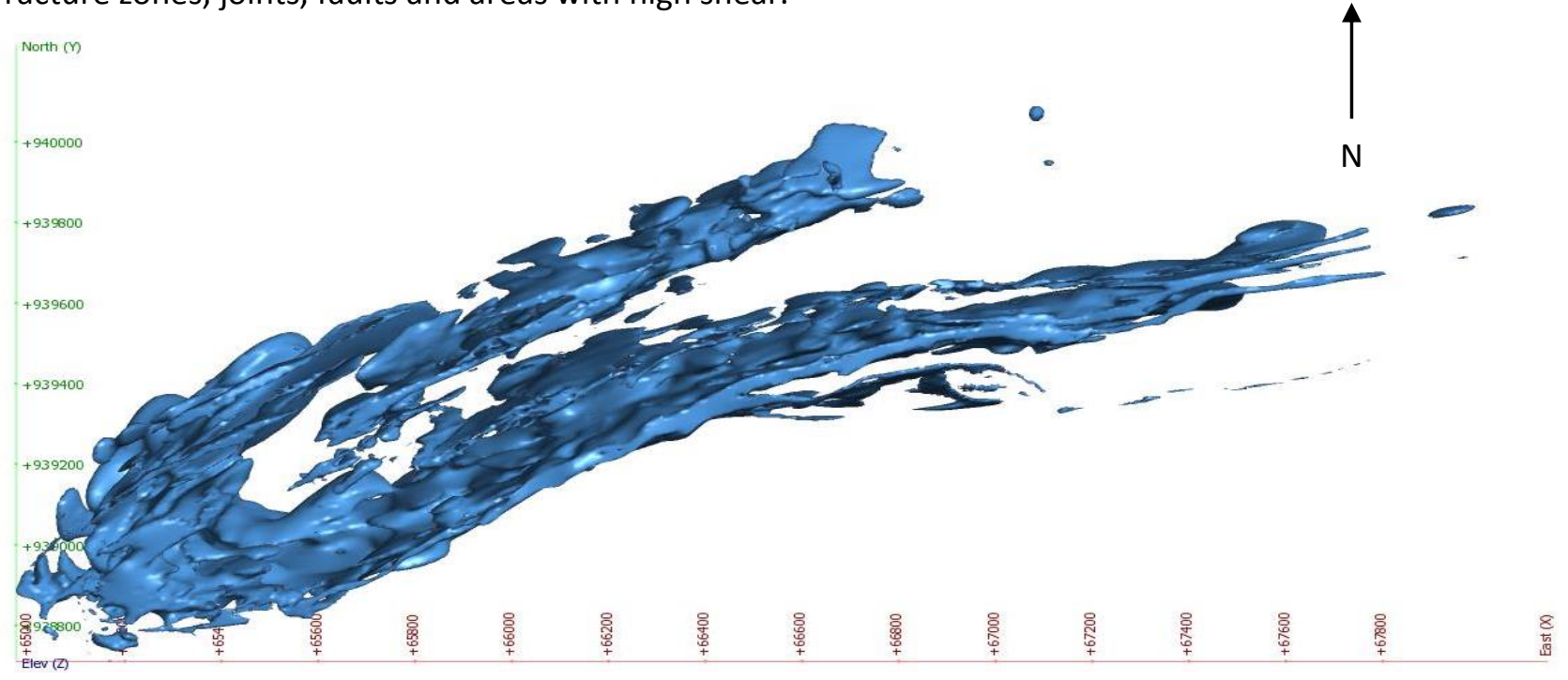

Figure 1 Horizontal projection showing the occurrence of iron oxide mineralisation in the Ørtfjell area. Drill core data digitalisation and manipulation 
The Kvannevann underground mine was established in 1999 underneath the abandoned Kvannevann open pit, which had been in operation for a short period between 1981 and 1982. Only small volumes of ore were mined during this period of operation. The former pit bottom at an average elevation of $400 \mathrm{~m}$ above sea level forms the upper extent for the present Kvannevann underground mine.

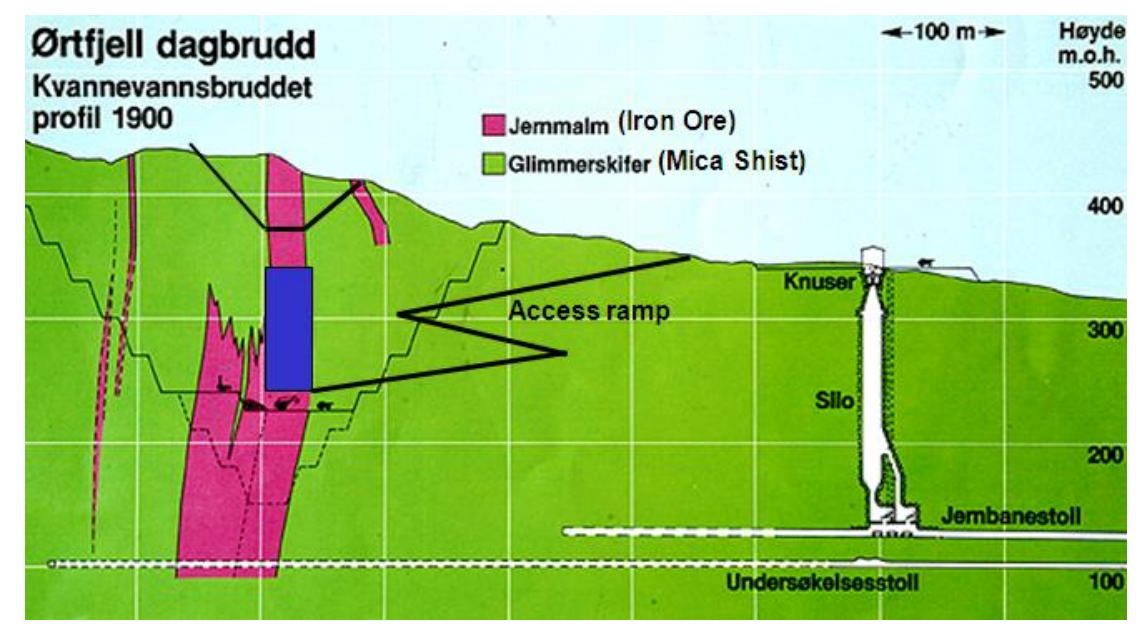

Figure 2 Vertical projections show the orebody occurrence in the Ørtfjell area, illustrating the old open pit, the access ramp to the underground mine and the mined area (dark rectangle)

Sublevel open stope mining has been used over a total length of 1,200 $\mathrm{m}$ of the Kvannevann orebody. The main, and first production level, was established at $250 \mathrm{~m}$ above sea level. A total of 16 stopes on average $60 \mathrm{~m}$ long, $30 \mathrm{~m}$ wide and $100 \mathrm{~m}$ high were aligned along the orebody. These were separated by a number of $30 \mathrm{~m}$ thick vertical pillars. The crown pillar is on average $30 \mathrm{~m}$ thick and separates the bottom of the open pit and underground operation.

Production drilling is carried out from production drifts at level $320 \mathrm{~m}$. A standard $360^{\circ}$ fan is drilled every $3 \mathrm{~m}$ with hole lengths chosen to encompass the iron ore. Additional production drilling is done from level $250 \mathrm{~m}$ upwards to create a funnel shaped design for the lower part of the stope.

Since 2007 parts of the crown pillar within the centre part of the mine have been blasted for stability field test reasons (refer to Sections 7 and 8 ) and to increase the mine production.

The extractable ore in the Kvannevann Mine is estimated at 44.8 million tonnes (Table 4) based on sublevel caving between level $219-123 \mathrm{~m}$ above sea level. The average iron content is estimated at $33.5 \%$, including a magnetite content estimated at 3.5\%. The waste rock composed of intrusions in the ore and form the side walls has been estimated to contain $11 \%$ Fe mainly bound to silicates and not as iron oxides.

The available data was essential to calculate the mineable ore reserves on the basis of a given cutoff for the mining block under consideration. They were also satisfactory to estimate the tonnage and Fe-levels of the still existing crown and vertical pillars of the Kvannevann Mine.

\section{$4 \quad$ Rock mechanics and rock stress}

Rana Gruber AS looks back to a very fruitful and inspiring cooperation with SINTEF (an independent research and development foundation in Norway) and The Norwegian University of Science and Technology (NTNU), Department of Geology and Mineral Engineering, which has lasted for many decades. The rock mechanics specialists played an important role during the period of open pit mining which started in the $\emptyset$ rtfjell area in 1981 and supported Rana Gruber AS during the construction work to build up the necessary infrastructure for this mining area. They have also been heavily involved in the planning of the Kvannevann underground mine. 
The $\varnothing$ rtfjell area, which hosts the Kvannevann Mine, is characterised by extremely high horizontal stresses which have to be taken into consideration during any type of excavation of rock in the area. The first observations of rock mechanic challenges were made during the early stages of the construction works and the late exploration phase of the Ørtfjell mining area.

During the construction of the underground silo and railway filling station which went ahead parallel to the establishment of a 2,400 m long exploration drift, a 3D in situ stress measurement was carried out in 1978. The measurements showed a horizontal stress parallel with the strike of the orebody of $20 \mathrm{MPa}$ and $15 \mathrm{MPa}$ normal to the strike, which is 10 to 15 times higher than the theoretical horizontal stress caused by gravity at an overburden of less than $100 \mathrm{~m}$. This caused severe spalling in the roof of the exploration drift.

Additional stress measurements were initiated in connection with Rana Gruber AS's plans to enter into underground mining operations conducting the Kvannevann orebody, and these confirmed the high horizontal stresses in the mining area (Table 1). During actual mining, a number of stress problems have been encountered causing serious operational problems. Locally, stress concentrations up to $65 \mathrm{MPa}$ have been measured in the mine at depths of approximately $100 \mathrm{~m}$.

Table 1 Mechanical properties of rocks in the Kvannevann Mine

\begin{tabular}{lccccc}
\hline Rock Type & $\begin{array}{c}\text { Uniaxial } \\
\text { Compressive } \\
\text { Strength } \\
\text { (MPa) }\end{array}$ & $\begin{array}{c}\text { Point Load } \\
\text { Strength } \\
\text { Index } \\
\text { (MPa) }\end{array}$ & $\begin{array}{c}\text { Young's } \\
\text { Modulus } \\
\text { (GPa) }\end{array}$ & $\begin{array}{c}\text { Poisson's } \\
\text { Ratio }\end{array}$ & $\begin{array}{c}\text { Unit Weight } \\
\text { (kg/m } \mathbf{3})\end{array}$ \\
\hline Ore & 60 & 3 & 30 & 0.22 & 3,800 \\
Dunderland schist & 48 & 4 & 18 & 0.10 & 2,800 \\
$\varnothing$ rtfjell schist & 65 & 4 & 24 & 0.15 & 2,750 \\
Limestone marble & 75 & 3 & 52 & 0.20 & 2,750 \\
\hline
\end{tabular}

The Dunderland schist comprising of mica schists and calcareous schists together with the iron ore horizons are the most prominent rock types in the Kvannevann area. These rocks have a relatively low strength, but are normally only moderately fractured (indicated by an average RQD value of 90 for the iron ore).

A. Myrvang (2009, written comm.) summarised the rock mechanics in the Kvannevann Mine as follows, "the rocks in the area initially are relatively weak and soft, but still quite compact and moderately fractured". Furthermore, he describes, "the rock stress problems of the type described as extraordinary in the world for a mine as this moderate depth".

\section{$5 \quad$ Impact assessment and $r$ isk analysis}

An impact assessment has been carried out in order to identify the consequences of the proposed change to a new mining method with respect to risks. The assessment fulfils the requirements set out by the Norwegian mining authorities and has been used as a key paper in the decision making process within Rana Gruber AS and its board of directors.

The report summarises the challenges and highlights the security measures necessary to handle and reduce risks and presents an action plan for the entire project and the time thereafter.

\section{Identified risk for sublevel caving at the Kvannevann Mine}

The project group identified the following advantages and disadvantages between open stope and sublevel caving. These advantages and disadvantages are not specific for the two mining methods in general. They apply to this investigation and from a Kvannevann Mine viewpoint. 
Table 2 Identified risk between sublevel open stoping and sublevel caving. ' + ' means there is a $r$ isk and ' - ' means is a small or no risk

Open Stope Sublevel Caving

\section{Production aspects}

Ore base

Flexibility

Relative vertical orebody

Several loading points

Drilling and blasting upwards

Waste rock dilution

Time for production

Movements of the side rock

Oversize rock frequency

Geometry of the orebody

Rock mechanic interaction

Sublevel height

Pillar recovery

Safety aspect

Work close to open rooms

Layouts and extraction sequence

Large scale stability

Air blast

\section{Mining economic}

Production cost in account to ore value in development drifts

Investment - asset tonnage

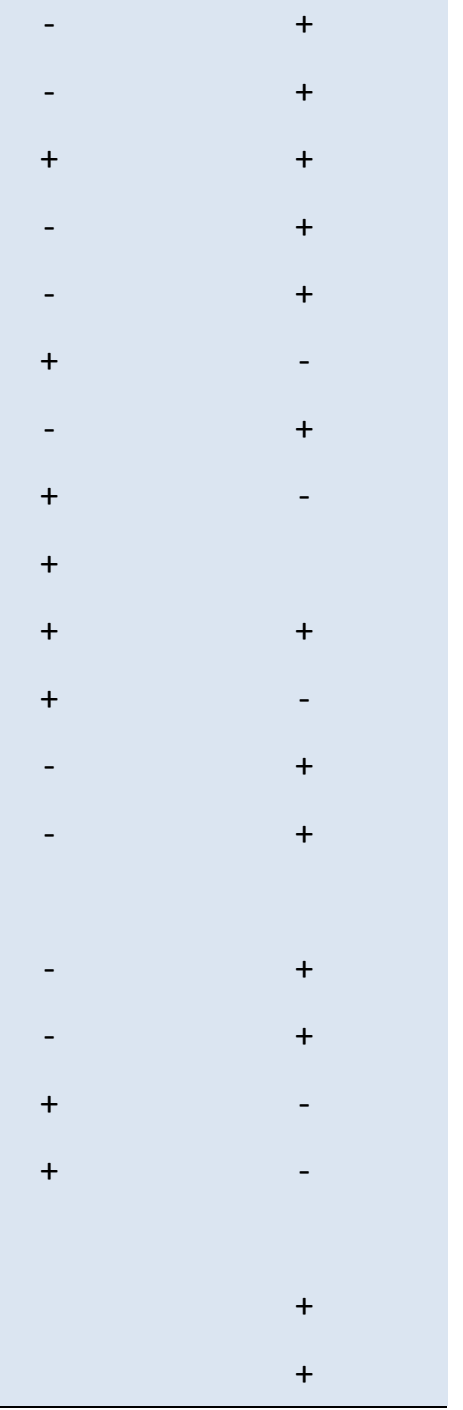

Based on the above identified risks, the project group concentrated on the main issues as summarised here:

- the geometry of the orebody

- pillar production

- large-scale stability

- a satisfactory caving of the hangingwall and footwall

- local stability of the hangingwall and the footwall

- location of the field tunnels, transport tunnels, shafts, crushing hall, etc.

- rock reinforcement

- extraction values and cutoff

- consequence and risk assessment. 
The project group recommended a change from open stope to sublevel caving for the operations at the Kvannevann Mine on the basis of the overall results obtained during the investigation programme.

\section{$7 \quad$ Preparation for sublevel caving}

As the result of the current open stope mining method, several crown and vertical pillars have been left as support for the upper mining level of the Kvannevann Mine. A prerequisite to succeed with sublevel caving is that all pillars have to be removed in order to achieve the necessary steady state caving behaviour.

The removal of the existing pillars is quite a challenge as it implies the risk of destabilisation of the mine with possible consequences to miners and losses of mineable ore within the upper level of the mine. To minimise the risk, a computerised simulation has been carried out which resulted in a working plan to accommodate activities.

With respect to the crown pillars, one important task will be to set aside a 'barrier crown pillar' in the centre dividing the current mine into a western and eastern part (Figure 3). It is most probable, that the crown pillar between vertical pillars 5 and 8 shown in Figure 3 will be chosen for that. Mining of the remaining crown pillars will thus start in the west from the outermost western part of the mine towards the barrier crown pillar. Thereafter, the activities will affect the eastern part of the mine before blasting the centre barrier crown pillar. The crown pillars will be drilled from the surface and blasted down to the present $250 \mathrm{~m}$ main level for loading.

The removal of the vertical pillars will follow thereafter and will be a part of the new sublevel caving mining method.

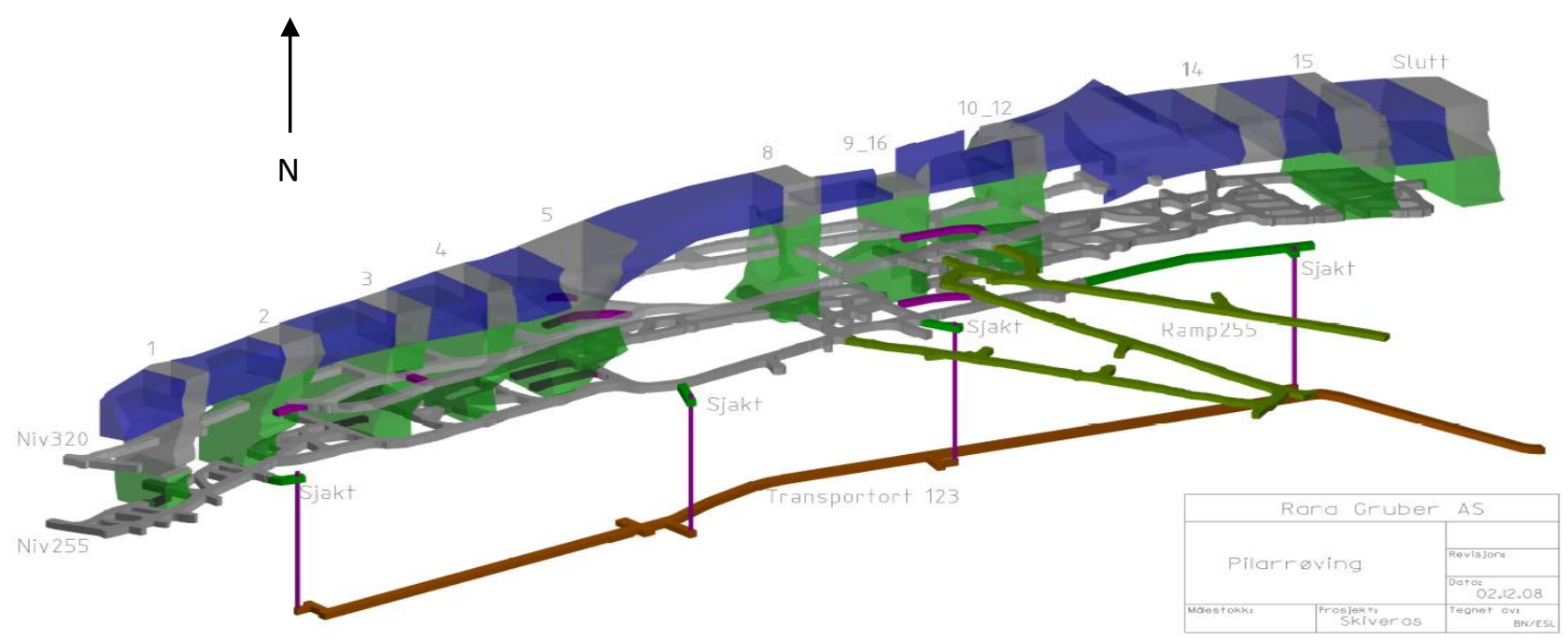

Figure 33 isometric view of level $250 \mathrm{~m}$. The figure illustrate the crown pillar and vertical pillars

\section{Caving - reality and simulation}

Sufficient and 'controlled' caving of the side walls of the deposit is required for mining by the sublevel caving method. It is therefore essential to build up confidence around this subject before any decision about a change in the mining method can be made. With the help of numerical modelling, carried out by SINTEF, combined with field tests, Rana Gruber AS gained sufficient reliable data which confirmed that sublevel caving will be feasible for the mining of iron ore at the Kvannevann Mine.

The investigation started with a computerised investigation of the consequences of the removal of the crown pillars from stopes 8 and 9 in the centre part of the deposit. These were shown to be negligible for the current main level at $250 \mathrm{~m}$. The subsequent physical removal of the above mentioned crown pillars during the field test verified the finding as there was not any evidence of impact on level 250 and just 
minimal caving of the sidewalls detectable. However, the subsequent robbing (removal of the upper part) of the vertical pillar between stope 8 and 9 resulted in a significant increase of caving, especially at the footwall of the deposit. In addition a very distinct fracture, parallel and aligned with the elongation of the stopes at a distance of approximately $25 \mathrm{~m}$ north from the edge of the open stopes was observed on the surface. This indicates that a removal of the pillars will promote significant caving of both the footwall and the hangingwall.

However, satisfactory caving proven at a small scale does not guarantee an overall well developed cave from the side walls over the total length of the deposit. It was therefore necessary to extend the computer evaluation with further numerical modelling, based on improved input data. Again SINTEF was engaged to run a new model assuming the removal of the entire rib pillars of the Kvannevann Mine. To define the degree of reliability and to demonstrate confidence, the model was tested by simulating the recovery of the pillar between stopes 8 and 9, the outcome of which, with respect to caving, has already been demonstrated from the field test. The computer simulation indicated a $10 \mathrm{~cm}$ deformation of the side rock towards the open stope. This would, in reality cause fractures parallel to the wall of the stope, a finding consistent with the results from the field test. Moreover, the digital calculation clearly demonstrated increased stress introduced into the remaining pillars, creating a risk of pillar collapse. This finding resulted in the conclusion to introduce, for safety reason, a 'barrier pillar' which will be recovered last. It is assumed that pillar 9 will be the safety pillar due to its size and location in almost the middle of the mine.

The computerised simulation also clearly demonstrated that caving will occur in areas of weakness crosscutting the orebody in the vicinity of stope 2 .

However, a computer simulation is not capable of predicting whether there will be regular caving as mining proceeds to deeper levels. This is required for sublevel caving to succeed. It cannot be excluded that larger caving may occur suddenly, resulting, as a worst case scenario, in a violent air blasts with consequences for both miners and the mine equipment. To prevent such incidents, the robbing of the vertical pillars and the mining of the remaining ore at level 250 has to be done successively and controlled by a carefully set operation scheduled from the start of sublevel caving. The iron ore produced from this operation is thought to build up a 'safety blanket' (also referred to as a 'dilution blanket') which at no time is to be intersected or partly removed from any area of the mine prior to initial caving of the side rocks of the mine. The challenge is not only to initiate and maintain a steady caving front but also to run at a high productivity and control the run of the mine by separating out waste rock interfaces.

Because of the high horizontal stress one must, however, expect significant rock pressure problems, particularly in the form of cracking in the roof of all drifts as well as in the walls of the rock shafts. SINTEF has conducted a comprehensive numerical model to address this phenomenon, and has made recommendations for necessary rock support tailored for each type of infrastructure established underground.

\section{$9 \quad$ Production plans}

According to our commitments and long-term agreements for the supply of iron ore concentrates to European steel mills, Rana Gruber AS requires an annual production of 2.7-3 million tonnes of crude ore with an average grade of $33 \% \mathrm{Fe}$.

The current mining plan involves a combination of open pit operations and underground mining in the Kvannevann Mine until the end of 2011. The ore production from the Kvannevann Mine is set to a minimum of 1.5 million tonnes per annum. This is done as a safety measure so as not to run out off crude ore and not to stress production from the Kvannevann Mine during the transition period from the open stope method to sublevel caving. Thereafter, all production will come from the Kvannevann underground mine.

During the transition period, 2009 to 2011, ore production in the Kvannevann Mine will be centred on ore from the remaining stopes and crown pillars. Estimated tonnage from crown pillars alone is 6.2 million 
tonnes. Vertical pillars will be prepared for removal following the transition over to sublevel caving. However, the first ore produced from sublevel caving will not enter the crusher before late 2011. The calculated total 6 million tonnes of vertical pillar ore will be produced successively from three sublevels which contain 3.4 million tonnes (level 1), 2.2 million tonnes (level 2) and 400,000 tonnes (level 3).

As stated before, vertical pillar ore will function as a safety blanket until sufficient caving from the side rock has taken place. This reduces the immediate availability of a considerable volume of ore. Mineable ore reserves of approximately 45 million tonnes will be available from the next sublevels between 219 to $123 \mathrm{~m}$ above sea level. This ore will be mined from 2011. With an annual production of 3 million tonnes of crude ore, the ore reserves of the entire sublevel package will last for a period of 18 years, based on an average ore excavation of $7 \mathrm{~m} /$ year over the entire mine.

\section{$10 \quad$ Mining cost for sublevel caving versus open stope method}

Future mining costs have been calculated to compare the two different mining methods against each other. It should be noted that the conclusions below are only valid for the Kvannevann Mine and should not be applied in general.

The calculation illustrates a difference in mining costs between the two different mining methods. This is partly due to higher ore recovery from the establishment of development drifts for the new mining method. The most important and significant difference in cost performance is, however, connected to the investment cost per available mine tonnage. A saving of more than $\mathrm{A} \$ 0.39$ per tonne (run of mine ore) for the sublevel caving compared with the open stope method. This is due to a doubling of available ore tonnage for the sublevel caving method.

This favours a decision for sublevel caving. Moreover, cost estimations have been performed to examine the difference between four and five sublevels within one block. The calculation clearly illustrates that the four level alternative is more cost effective. A five level solution increases the mining cost by almost $A \$ 1.94$ per tonne. This conclusion is consistent with the requirement from rock mechanics to avoid five sublevels within one block due to the high horizontal stress in the area.

\section{Interaction between Fe content, loading rate and cutoff}

Because of the low in situ iron content of the iron ore (Table 3 ) it is important to avoid any significant blending of the ore with waste rock originating either from intrusions in the ore or from the side rock. In order to hinder mixing of iron ore with side rock due to caving of the side walls, it has been decided, as explained earlier, to use ore from the vertical pillars as a security blanket to maintain a feasible iron content of the ore and obtain a satisfactory extraction rate (the blanket also provides a layer of protection against the risk of airblasts). This measure, certainly, will 'cost' iron ore in the order of $4 \%$ of the total amount of the mass of the vertical pillars in the first step, but will be more than repaid during the period of sublevel caving. However, in spite of the above security measures, the degree of caving of the side rock and the loading rate will have a major impact on the content of iron in the run of mine.

Table 3 In situ iron content per level for drillable ore

\begin{tabular}{cc}
\hline Level & In Situ Iron Content (\%) \\
\hline 259 & 33 \\
$259-187$ & 33.4 \\
187 & 22.5 \\
\hline
\end{tabular}

Early caves of the side rock are expected to contribute to a higher loading rate for the upper levels. On the other hand it may result in lower iron content for the mined ore if the 'front ore' gets thin. Late caves of the side rock necessarily have to result in lower loading rates for the upper levels with higher iron 
concentrations for the mined ore as there will be little blending of the ore and there is the requirement to leave the security blanket untouched. The estimated average iron content for the entire sublevel height is 31.7\%, with varying extraction rates between 83 and 101\% (as shown in Table 4).

Another variable of influence is the waste rock dilution in the ore which is difficult to calculate precisely due to the folding of the orebody. The front ore layer against the waste rock has to be maintained under any circumstances. Even a thinning out of the layer will contribute to a lower iron content in the loaded ore.

Table 4 Relationship between recovery and loading rate

\begin{tabular}{cccccc}
\hline Level & Tonnage & $\begin{array}{c}\text { Iron Content } \\
\text { (\%) }\end{array}$ & $\begin{array}{c}\text { Total Extraction } \\
\text { Tonnage }\end{array}$ & $\begin{array}{c}\text { Iron Content } \\
\text { (\%) }\end{array}$ & $\begin{array}{c}\text { Loading } \\
\text { Degree (\%) }\end{array}$ \\
\hline 219 & 8.8 & 33.2 & 9.2 & 32.3 & 94 \\
187 & 10.7 & 33.6 & 12.6 & 32.3 & 101 \\
155 & 12.6 & 33.6 & 10.4 & 31.4 & 83 \\
123 & 12.7 & 33.4 & 10.2 & 30.7 & 84 \\
\hline Total & 44.8 & 33.5 & 42.4 & 31.7 & 90 \\
\hline
\end{tabular}

The relationship between the loading rate and the iron content in the run of mine ore has been calculated by means of a computerised data simulation for the ore of the Kvannevann Mine. It is essential that the dressing plant be supplied with crude ore that does not vary significantly in the iron content. In addition, the amount of iron in the crude ore delivered to the dressing plant has to be high enough to guarantee an economic operation.

Assuming a) today's productivity and modern iron ore pricing; b) a continuous and 'controlled' caving of the side walls with an iron content of $11 \%$; c) a constant iron content of $63.5 \%$ in the iron ore concentrates from the dressing plant; and d) a loss of iron in the tailings of $9 \%$; the maximum loading rate to be economic is $80-85 \%$ with a minimum iron content of the loaded and delivered ore of $30 \%$. This results in an extraction tonnage of approximately 40 million tonnes for the ore between 219 and $123 \mathrm{~m}$ of the Kvannevann Mine (Table 5).

Table 5 Available tonnes depending on loading rate

\begin{tabular}{ccc}
\hline $\begin{array}{c}\text { Loading } \\
\text { Rate (\%) }\end{array}$ & $\begin{array}{c}\text { Extraction } \\
\text { Tonnage (Mt) }\end{array}$ & $\begin{array}{c}\text { Iron Content } \\
\text { (\%) }\end{array}$ \\
\hline 60 & 28.1 & 33.3 \\
65 & 30.5 & 33.2 \\
70 & 32.8 & 32.8 \\
75 & 35.2 & 32.3 \\
80 & 37.5 & 31.7 \\
85 & 39.9 & 30.9 \\
90 & 42.2 & 30.0 \\
95 & 44.6 & 29.0 \\
100 & 46.9 & 28.0 \\
105 & 49.2 & 26.9 \\
110 & 51.6 & 25.9 \\
\hline
\end{tabular}




\section{Mine layout}

With a total sublevel height of $130 \mathrm{~m}$, the orebody will be divided into four horizontal sublevels at 219,187 , 155 and $123 \mathrm{~m}$ above sea level. Level $123 \mathrm{~m}$ is chosen to be the main transport level. Due to the horizontal extent of almost $1.2 \mathrm{~km}$ in the east-west direction, the orebody, and consequently each level, will be divided into three different blocks - a western, central and eastern block. A preparation drift located $20 \mathrm{~m}$ from the ore footwall to the south will be established on each level. Transverse sublevel caving will be used since it is more cost effective compared with longitudinal sublevel caving. The distance between crosscuts will be $22 \mathrm{~m}$ and the drift cross section will be $6 \times 5 \mathrm{~m}$.

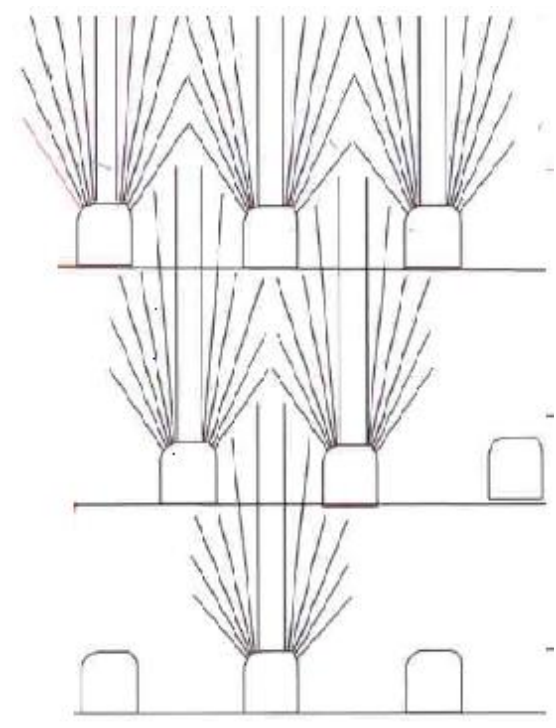

Figure 4 Demonstrating the drift cross section, crosscut and location of the drift

Following the excavation of the development drifts, ore passes with a diameter of $3 \mathrm{~m}$ will be raise bored in each of the three blocks to link the sublevels to the $123 \mathrm{~m}$ main level. The eastern block will get one extra ore pass to reduce the risk of a stop in production due to bottlenecks in the overall mining activities and to increase the efficiency of waste rock handling.

The ore passes will be located at a distance of $50 \mathrm{~m}$ from the orebody. The ore passes will be equipped with grizzlies to prevent oversize rock from blocking the shaft hoisting system. The ore pass from the central block will be connected through feeders directly to an underground crusher. From the other ore passes, the ore will be transported by trucks to the crusher.

A crusher station equipped with a primary jaw crusher will be established on the main level about $85 \mathrm{~m}$ south of the orebody. During construction of the crusher hall, heavy rock support measures have been necessary to cope with the high horizontal stress. From the bottom of the crusher hall, a conveyor belt is planned to transport the crushed ore to the existing main underground silo of the mine. The conveyor belt tunnel will have an upward inclination of $15^{\circ}$ and a length of $550 \mathrm{~m}$. All construction work in the mine is being carried out by Rana Gruber AS's mother company, LNS.

The old exploration adit established between the years 1978 to 1982 has already been upgraded to a larger dimension and provided with good road conditions. For the immediate future, the drift will function as an additional ventilation intake and as an emergency access for the mine in case of any unexpected impact on the present underground infrastructure. It is considered that the adit will become the new main entrance to the mine when ore production has moved to the lower levels.

Sublevel caving will require the construction of $1,800 \mathrm{~m} /$ year of development drifts. It is expected that $70 \%$ of the total length will be in ore. The sublevel block between 219 and $123 \mathrm{~m}$ is estimated to require $32,300 \mathrm{~m}$ of drifts. 
A standard production fan will contain 12 drill holes, with the longest hole at $38 \mathrm{~m}$. This will result in an average of 302 drill metres for each established production fan. The hole diameter is set to vary between 89-95 mm. The greatest distance between the end points of the drill holes of one fan will be $2.7 \mathrm{~m}$. Each fan will be inclined at an angle of $80^{\circ}$ from the horizontal. The distance between each fan will be $3 \mathrm{~m}$. One blast is calculated to free 6,000 tonnes of ore for each $3 \mathrm{~m}$. The specific value for production drilling is calculated at 0.047 drill $\mathrm{m} / \mathrm{t}$.

The opening of the cave will be carried out through the use of local opening raises and drilling against the hangingwall. The raises will be located $6-18 \mathrm{~m}$ from the hangingwall toward the ore, depending on the inclination of the contact.

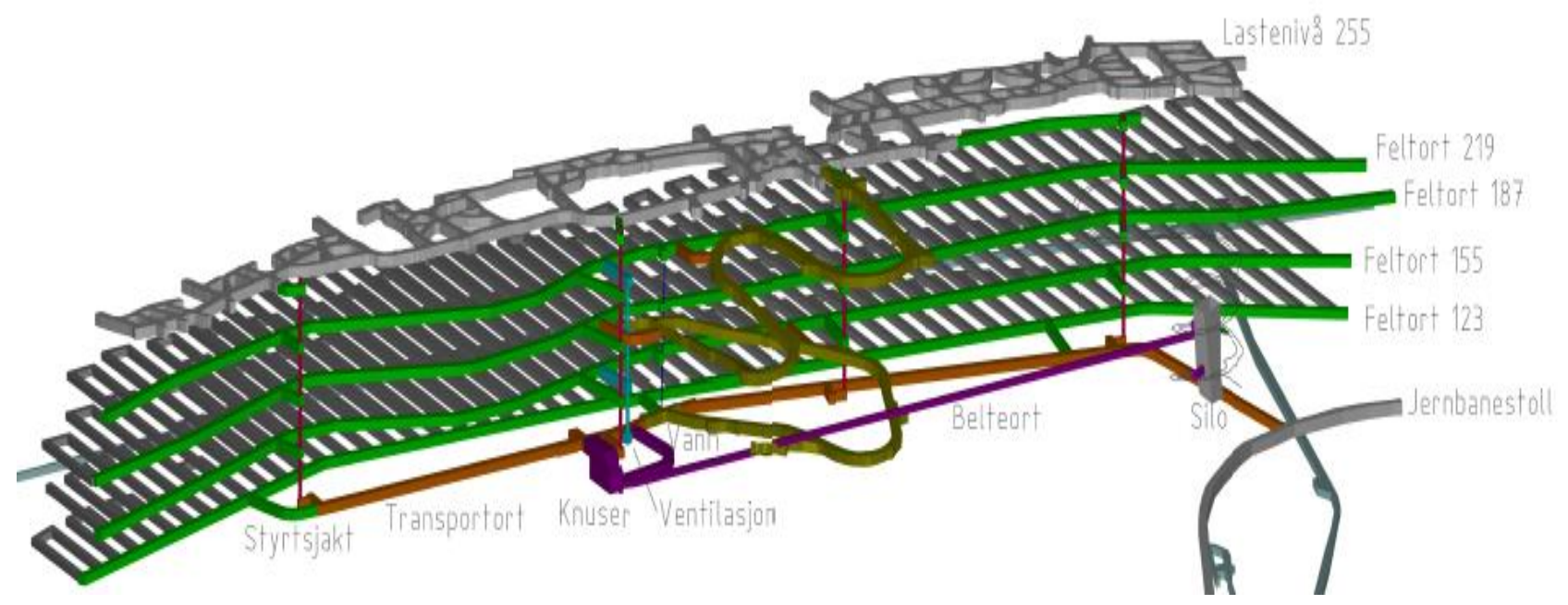

Figure 5 The figure illustrate the mine layout for sublevel caving at the Kvannevann Mine. The current production level of $250 \mathrm{~m}$, the different levels during sublevel caving, ore shaft, ventilations shaft, placement of the crusher and the attached conveyor belt, etc.

\section{Conclusion}

The Kvannevann Mine is currently operated using the method of sublevel open stoping. A transition to sublevel caving has been proposed to extend the life of the mine, increase production and reduce mining costs.

An abnormally high horizontal stress makes the mining at the Kvannevann Mine extraordinary. It requires special safety measures with respect to rock support during mining.

Computer simulations and field tests have been used to gain confidence regarding the selection of sublevel caving as a feasible alternative.

The investigations have resulted in a detailed plan as guidance for the transition from sublevel stoping to sublevel caving.

One important safety measure is to establish a safety blanket of ore as a front against caves from the side walls of the deposit as there is still some uncertainty connected to the degree and time of caving. An emergency adit has been established should the new mining method have unexpected impacts on existing underground infrastructure of the mine.

\section{Acknow ledgement}

The author thanks all participants in the project group. Special thanks are extended to Ingemar Marklund and Bill Hustrulid who have greatly contributed to this paper regarding the subject of loading rates, risk assessment and general issues in sublevel caving. More special thanks go to Arne Myrvang for his help on rock mechanics evaluations. 
